\section{REDIMAT}

Journal of Research in Mathematics Education
Hipatia Press

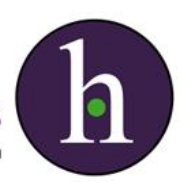

Instructions for authors, subscriptions and further details:

http://redimat.hipatiapress.com

\title{
How Can I Help my Students with Learning Disabilities in Mathematics?
}

Gracia Jiménez-Fernández ${ }^{1}$

1) University of Granada, Spain

Date of publication: February $24^{\text {th }}, 2016$

Edition period: February 2016-June 2016

To cite this article: Jiménez-Fernández, G. (2016). How can I help my students with learning disabilities in Mathematics? REDIMAT, 5(1), 56-73. doi: 10.4471/redimat.2016.1469

To link this article: http://dx.doi.org/10.4471/redimat.2016.1469

\section{PLEASE SCROLL DOWN FOR ARTICLE}

The terms and conditions of use are related to the Open Journal System and to Creative Commons Attribution License (CC-BY). 


\section{How Can I Help my Students with Learning Disabilities in Mathematics?}

Gracia Jiménez-Fernández

University of Granada

(Received: 10 March 2015; Accepted: 14 February 2016; Published: 24 February 2015)

\section{Abstract}

Learning Disabilities in Mathematics (LDM) or dyscalculia are a frequent and disruptive problem within schools. Nevertheless, this problem has received little attention from researchers and practitioners, if compared with the number of studies published on disabilities in reading. Therefore, teachers do not have enough guidance to help children overcome their difficulties. Consequently, educators, practitioners and teachers are in need of some guidelines which help them choose teaching methods that are adapted for children with LDM. This paper proposes an interventional framework for improving skills in children who show problems in learning basic mathematics. Concretely, it suggests some guidelines which are focused on number sense and problem solving, two of the most important mathematical areas.

Keywords: Learning disabilities, mathematics, educational guidelines, number sense, problem solving 
REDIMAT, Vol. 5 No. 1 February 2016 pp. 56-73

\section{¿Cómo Puedo Ayudar a Mis Estudiantes con Dificultades de Aprendizaje de las Matemáticas?}

Gracia Jiménez-Fernández

Universidad de Granada

(Recibido: 10 Marzo 2015; Aceptado: 14 Febrero 2016; Publicado: 24 Febrero 2016)

\section{Resumen}

Las dificultades en el aprendizaje de las Matemáticas (DAM) o discalculia son un problema frecuente y disruptivo en las aulas de Educación Primaria. Sin embargo, este problema ha recibido muy poca atención desde la investigación e intervención si lo comparamos con el gran número de estudios publicados sobre las dificultades de aprendizaje de la lectura. Por ello, los maestros no tienen a su disposición suficientes materiales que puedan guiarles para ayudar a estos niños a superar sus dificultades. Consecuentemente, los profesionales de la educación necesitan conocer directrices que les permitan elegir la metodología didáctica que se pueda adaptar a los niños con DAM. Este artículo propone un marco general de intervención para mejorar algunas habilidades en niños que manifiestan problemas en el aprendizaje de las matemáticas. Específicamente, se sugieren directrices y orientaciones centradas en el sentido del número y en la resolución de problemas, dos de las áreas con dificultades más importantes.

Palabras clave: Dificultades de aprendizaje, matemáticas, orientaciones educativas, sentido del número, resolución de problemas 
M athematics is one of the basic instrumental tools of learning and, along with language, contributes to enhancing logical thinking as well as being a fundamental basis for which other fields of knowledge relies on. Therein lays the importance of teaching mathematics in Elementary Education, which should be regarded as an essential goal to be achieved at this schooling stage.

However, learning mathematics is not easy and its rate of failure is usually one of the highest, particularly in the final stages of Elementary Education (Alsina i Pastells, 2007). In fact, a significant percentage of students consider mathematics is a complicated subject and consequently show a certain lack of interest in it. Nevertheless, some children find more difficulties in this field than expected. These children will be referred in this paper as children with Learning Disabilities in Mathematics (LDM).

LDM are also called dyscalculia that is, difficulties in the production or understanding of quantities, numerical symbols or basic arithmetic operations. The prevalence is considered to be around $6 \%$ and its symptoms become evident in about the second grade of Elementary Education (Shalev, 2007). Current data indicate that this learning disability is a brain-based disorder with a familial-genetic predisposition (Shalev \& Gross-Tsur, 2001). Although people with LDM have an average or above average intelligence and may even stand out in fields other than mathematics, they find it difficult to estimate distance, size or time and usually count on their fingers in order to work out simple operations (Landerl, Bevan, \& Butterworth, 2004). These kinds of situations are frequent in the daily live, and it is because of this, the problems associated with LDM may have huge negative impacts on children's social and, of course, educational areas.

Children with LDM can learn mathematical concepts but the progression they do in two years of schooling corresponds to what other students achieve in a year's time (Ortiz, 2009). Likewise, Blakemore \& Frith (2007) affirm that these children have a difficulty to learn but it does not make learning impossible, even though its development may be slower. Consequently, the learning processes of these students require additional and specific teaching methodologies.

Despite the high prevalence of the LDM and the negative impact it has for children who have them, until now there are very few articles that provide intervention guidelines for teachers and other educational practitioners. Therefore, the main goal of this paper is to present a brief review about some general strategies and guidelines research-based from 
Cognitive Psychology (e.g.: Artigas, 2011; Cohen, Dowker, Heine, Kaufmann, \& Kucian, 2013; Defior, 1996; Ortiz, 2009; Sans, 2008) and the Neuroscience (see interesting review Radford \& André, 2009). However, as Butterworth, Varma, \& Laurillard (2011 p. 1051) pointed out: "Although the neuroscience may suggest what should be taught, it does not specify how it should be taught". Similarly, Bruno, Noda, Aguilar, González, Moreno, \& Muñoz (2006) highlighted there are not many papers that focus on explain specific strategies and materials for children with special needs. In this sense, the present review aims to contribute to cover the gap between research and practice and offer some methodological strategies to compensate the LDM.

First, general intervention strategies will be presented, these strategies are general because they can be applied various areas of mathematics learning. Subsequently, this review will cover three of the main areas where children with LDM show more difficulties: number sense, basic arithmetic operations and problem solving. In each area, this paper will include suggestions evidence-based and concrete examples that can facilitate the use in the classroom.

\section{Characteristics of Children with LDM}

These characteristics will be presented in relation to the main fields of mathematical knowledge. These fields are the numerical sense, basic arithmetic operations and problem solving (Santiuste \& González-Pérez, 2005). These fields are considered to follow a pyramidal structure, being the number sense the base where the learning process of basic arithmetic operations (addition, subtraction, multiplication and division) and problem solving stand. Moreover, these specific fields of knowledge within mathematics are influenced by various cognitive processes such as attention, memory, language and knowledge of basic concepts (e.g. size or shape).

\section{Number Sense}

The number sense or numerosity concept is the ability to understand the meaning of numbers. This ability is ancestral and it is prior to language and 
reading, obviously, and is developed without need of any formal education at a very early stage.

The development of the number sense comprises different stages:

1. Development of a general number sense: innate ability with which we are able to differentiate between one and multiple elements.

2. Development of the verbal number sense: ability to associate a quantity with a specific word.

3. Development of the symbolic number system: ability to associate a quantity with a specific number.

4. Development of the representation of a numerical sequence, called mental number line: ability to represent numbers in a consecutive manner on an imaginary number line.

However, these stages do not develop linearly in all case; in this sense, the knowledge in one stage can facilitate the acquisition of others (see Dehaene, 2011 for details).

The number sense is primarily developed from informal and nonintentional learning, that is to say, through the child's every day experiences, without the need of formal learning. The number sense is a fundamental aspect in order to acquire a proper number processing ability. It is essential, for example, to the learning of basic arithmetic operations. In addition, there are other factors involved in the development of the number processing ability. These can be personal, like the intellectual ability, or environmental, like teaching at the school. In the same way, the number sense is the basis of several mathematical abilities such as numbering, mental arithmetic and estimation.

In this sense, some authors regard an inadequate development of the number sense as the core of the learning disabilities in mathematics, that is, children with LDM do not develop this knowledge or they develops more slowly than typically developing children (Berch, 2005). However, although the development of number sense in children with LDM does not occur spontaneously (incidental fashion), they can acquire it with explicit instruction (see this paper, section 4.1.).

The deficit in the development of number sense makes children with LDM have problems to associate numbers and objects; to understand that each 10 units make up a ten; for counting; to understand the place value of figures in a quantity (e.g. 3 does not have the same place value in 328 as in 
23); to sort numbers in decreasing or increasing order; to decompose and compose numbers (e.g. identify units, tens, hundreds, etc.); and/or to complete a sequence of related numbers (e.g. 147-140-133...).

Moreover, these children fail at a high rate in recalling numerical information from the long-term memory, i.e., knowledge stored over a long period of time, often over the entire life span of the individual. The type of mathematical knowledge stored in this type of memory is, for example, the multiplication tables and the learning and storing of this kind of information is a hard task for children with LDM. In the same way, they usually make mistakes when reading and writing multi-digit numbers, especially those which have zeros.

These problems remain throughout the school period, so these children's' progress is different to that of their partners. This is generally slower and lacking the necessary automation to do basic mathematical procedures.

All in all, the learning of mathematics stands upon an innate ability called number sense, even though its learning context corresponds to that of the school. This skill is not taught but gained incidentally from a repetition of experiences with the environment. This innate ability would be the main explanation for learning disabilities in mathematics. However, more research is needed in order to set its limits and define the exact cause of the problem.

\section{Basic Arithmetic Operations}

Basic arithmetic operations (BAO) are addition, subtraction, multiplication and division. The learning of these operations is an essential goal in all stages of Elementary Education.

Children with LDM get to know the different concepts related to basic arithmetic operations but do not proceed automatically. In this sense, they do not use the appropriate arithmetic strategies for their level of development (e.g. counting from the addend of greatest value), nor automate basic combinations of numbers (e.g. 2+2). Consequently, these children take more time to do an operation and usually need complementary materials, tangible or visual, for help (e.g. using sticks or counting on their fingers). Moreover, they often have problems with the spatial location of numbers when doing operations (e.g. $352+47=822$ ) and make mistakes in 
the direction of the operation (they start from right to left). In general, these students make many procedural errors, especially in operations with borrowings.

Going into more into detail, they may find more difficulties with subtractions since it is a complex concept that requires having acquired the concept of reversibility. In this respect, one of the most common mistakes is to subtract the bigger number from the smaller without considering if it is the minuend or the subtrahend.

Another frequent mistake is confusing mathematical signs, doing the wrong operation and sometimes mixing addition and subtraction. Furthermore, they usually omit or change some step of the algorithm; for example, they only do an operation with the first number in a division with a two-figure divisor.

The division is the most difficult arithmetic operation for children with learning disabilities in mathematics. Some of the reasons are the following: it is essential to have fully acquired the other BAOs upon which the division stands, and also it is the only operation which has two results (quotient and remaining) and has to be reviewed because the remaining cannot be bigger than the quotient, for example.

Concerning calculation, these children do not only have trouble doing BAOs but also with the content that is delivered during the last years of Elementary Education, like operations with fractions and decimal numbers. In most of the cases, these difficulties are due to an inappropriate acquisition of basic arithmetic operations. Therefore, it is crucial to ensure that children, especially with LDM, are taught new knowledge only when previous knowledge has been fully understood.

\section{The Importance of Error Analysis}

Error analysis is considered to be an exact way to detect and determine children's difficulties. Research clearly shows that children with LDM do not make mistakes by chance or as a consequence of their lack of attention, but because of systematic wrong ways of procedure or knowledge (Defior, 1996). Teachers should regard errors as signs of deficit, being these ones the point of departure from which solutions for the student's difficulties should start. Errors should be presented as normal things, as part of the whole process of improvement. Therefore, if a child makes a mistake in 
computation the teacher has to analyze the error pattern and encourage the student to do the operation again, this time with the support that the error analysis has determined.

The identification of the error pattern will let us put all complementary strategies into operation so that the child can overcome it. Seven error patterns, which frequently appear in arithmetic operations, have been identified (Enright, 1989). They are:

1. Borrowing from another operation. This mistake indicates that the child has not understood correctly the place value of numbers or the steps to follow in order to do an operation. For example, let's assume the child has to do the subtraction $460-126$ and the solution they propose is 340 . The error is due to the 0 in the minuend because this number has different values in additions, subtractions, multiplications and divisions and they get confused. Another error of this kind would be 460-126=346.

2. Replacement in the process. Errors are due to the substitution of one or several steps of the algorithm for another that has been made up or is wrong. In the following example, it is shown how the student only does the first multiplication and then copies the rest of the numbers: $232 \times 3=236$.

3. Omission. The error comes after the omission of any of the steps of the algorithm (the child does not invent it, only forgets it). In the following example, it is shown how the student only pays attention to the decimals and forgets about the integers: $2.75+0.44=1.19$.

4. Direction. Errors in the order or direction of the proceedings (they start from left to right), even though the computation is correct.

5. Place. The calculation is right but the student changes the place of the elements when they are writing the operation. For example: $9+5=41$.

6. Operational symbols. The error is due to a wrong interpretation of the operational symbol or that the sign is simply ignored.

7. Guessing. Sometimes, errors do not follow any logical explanation. This indicates that the basis of the operations has not been understood.

Other types of error that appear frequently are:

Mismatching of quantities when doing an addition or when organising intermediate products in multiplications or the omission of zero (e.g.: it is thought that $0+\mathrm{N}=\mathrm{N}$, for example: $208-62=166$ ).

Error patterns of children with LDM have to be studied carefully in order to detect and correct them. Teachers have to learn to distinguish systematic errors which result from a lack of knowledge or the use of 
wrong strategies from those which are due to an isolated lack of attention.

As Defior (1996) has pointed out, systematic errors are not solved by doing more practice and exercises but by a teaching method focused on every mistake considered individually.

\section{Problem Solving}

Problem solving is a complex area of mathematics, which requires knowledge from both of the above-mentioned areas (number sense and basic arithmetic operations) and language knowledge. Children with LDM difficulties in problem solving relate to an inadequate way of carrying out the different processes (representation and planning, carrying out of the operations and reviewing and evaluation tasks) that are implied in this activity (Romero \& Lavigne, 2005).

Difficulties in the representation and planning processes. In order to solve a problem, it is necessary to build a mental representation of the problem statement. That is to say, the student has to understand the terms in which the problem is expressed and relate them. Translating the narrative language to mathematical language is essential to understand it. Children with learning disabilities in mathematics can find this translation process difficult and, consequently, have more difficulties to build a representation of the statement. These problems are more visible when the semantic structure of the problem is complex, for example a comparison, or if the solution of the problem only results by doing multiple steps, like two or more arithmetic operations.

Furthermore, it is important to highlight that some of the children that have difficulties in problem solving also have problems with reading comprehension. Consequently, the lack of reading comprehension explains the fact that these children usually do arithmetic operations and algorithms correctly but make mistakes translating the problem.

One of the most frequent mistakes that children with LDM make is called "direct or literal translation". This incorrect strategy consists of focusing on looking for the numbers that appear in the problem statement as well as some key words to identify the operations they have to do. For example, the problem "Pablo had 16 Euros and he spent half of his money. His grandfather gives 12 Euros more. How many Euros does Pablo have? Children with LDM pay attention to the word "more" and some numbers 
and they solve (incorrectly) the problem with the operation $16+12$. Likewise, children with LDM have trouble identifying pertinent information and discarding that which is not necessary for the resolution of the problem.

Difficulties carrying out the operations. It is possible for a child with LDM to have translated, embedded and planned a mathematical problem correctly but to make a mistake doing the operation due to any of the problems we commented previously about counting.

Difficulties during the reviewing and evaluation processes. While the student is solving the problem, they should control all the process so that it results in a solution that suits the plan. In other words, the student have to review what has been done, along with the final result, in order to check if it fits the plan and to identify and correct, if necessary, any possible error. As a general rule, children should turn to their mathematical knowledge to review and control the efficiency of the methods they are using. However, children with LDM do not usually review the final solution or, if done, they have problems to differentiate when something is right or wrong, so they tend to consider their work correct even when it is wrong.

Apart from these behavioural features concerning number sense, computation and problem solving, children with LDM usually show some cognitive deficits such as a lack of attention, memory problems, visualspatial problems and difficulties in processing audible information. It is important to point out that children with LDM do not necessarily present all characteristics that have been mentioned, since, as we have already said, this is not a uniform group. The evaluation and analysis of errors will help to determine the concrete characteristics that a child with LDM presents and use them to design an adequate educational treatment for the student.

\section{General Strategies of Intervention}

As in the case of other learning disabilities, the first step is to plan a specific educational intervention to identify the child's particular deficits and abilities. This identification is comprised from both the assessment results and the error analysis. Once the attainment of the student has been defined, the teacher will be able to work with some clear and quantifiable objectives. As noted Alsina i Pastells (2007), the traditional methodology based on the repetition of mathematical activities makes no sense. Sometimes even the 
repetition of activities is applied as a punishment for their poor performance, which has emotional consequences beyond academic scope. In this respect, the solution lies on activating mental processes involved in the different math activities, specifically, the general strategies of intervention (Kaufmann, 2008; Martínez, 2010; Sans, 2008) should be based on:

- The usual use of contexts that simulate problems and arithmetic operations relevant to their daily life.

- Procedures that include guidance by direct demonstration along with verbal instructions and/or consecutive attempts by the child with feedback (e.g. making rules explicit in order for the child to achieve autonomy).

- The assurance that all necessary previous knowledge is well developed before starting to learn new content.

- Include scaffolding teaching practices of the content, using a multisensorial approach.

- A learning process built on sequences which go from abstract to concrete things.

- Include, from time to time, review exercises which represent varied topics and different situations so that the child can fully master the ability.

- The suggestion of individual assignments to support specific difficulties.

- Give extra time to solve mathematical tasks at home and at the school, since children with LDM have not yet automated the basic processes.

- Treatment of possible associated disorders such as dyslexia (GrossTsur, Manor \& Shalev, 1996) and/or attention deficit hyperactivity disorder (Monuteaux, Faraone, Herzig, Navsaria \& Biederman, 2005).

\section{Strategies Specifically Adapted According to the Field of Difficulty}

It is very important to bear in mind that mathematical skills are heterogeneous and a mathematical learning demands a wide range of cognitive mechanisms. There are differences among learning multiplication tables, doing estimations of the number of elements or using the area of the 
circle formula in a problem. Thus diverse kinds of abilities take part even in the same mathematical operation. The heterogeneity of mathematical knowledge makes it clear that children with LDM will not be a uniform group, as it is in other learning disabilities. Therefore, it is essential to determine their specific symptoms in order to create an educational intervention that is specific to their needs.

Although many processes are involved in the learning of mathematics, this review focus on the three areas of significant importance in Elementary School and which seems to be the most problematic for children with LDM.

\section{Number Sense}

Prior research has shown that the core of the deficit presented by children with dyscalculia is an inappropriate development of the concept of number or number sense (e.g. Butterworth, Varma and Laurillard, 2011; Dehaene, 1997; Otálora Sevilla \& Orozco Hormaza, 2006). Therefore, an assessment of this aspect may detect future difficulties in mathematics (see details of number sense development in Sowder, 1992).

The first step to reinforcing the concept of number sense is to strengthen basic concepts which were taught in previous stages of education (e.g. in kindergarten). In this sense, it is sometimes necessary to teach the principles of quantity, order, size, distance and space. The teacher must begin teaching these basic concepts using concrete and familiar materials like seeds or pencils. Once children have fully acquired these concepts, it is advised that the teacher start working on activities which reinforce the meaning of numbers such as magnitude activities (see Figure 1) and/or simple numerical sequences.

Mark the biggest number
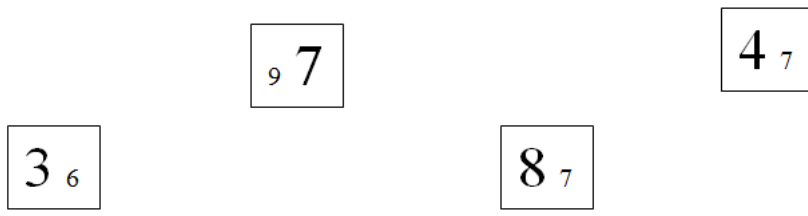

Figure 1. Activity to reinforce the number magnitude. 
In any event, the teaching process must move slowly from concrete to abstract concepts. Therefore, teachers should use tangible materials and other supportive measures to support and build upon the process of number abstraction (Chan, Au \& Tang, 2014).

The mental number line can be reinforced by using real number tables and lines available in the classroom or written in the students' exercise books. Likewise, it would be useful for them to count objects or events connected to real life such as lists of attendance, items available in class, schedules, votes, heart beats or Parcheesi.

In addition, it is necessary to reinforce the understanding of the place value of numbers. In order to understand this concept, it is important to repeat and make clear that multi-digit numbers are numerical expressions to be decoded in a process that follows certain rules. In other words, every single number has its own value depending on the place they are in. It is highly recommended that you use tangible materials such as sticks or an abacus to strength the composition/decomposition process of numbers. An example of an activity to improve writing numbers using templates is shown in Table 1.

Table 1

Example thought to improve the writing of numbers by means of templates (Adapted from Martínez, 2010).

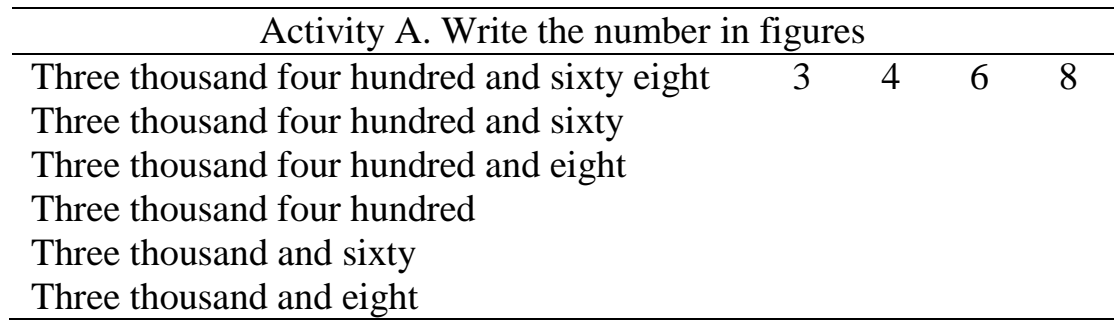

\section{Basic Arithmetic Operations}

Error analysis will provide us with concrete guidelines for the intervention in BAOs. However, it will be necessary to strengthen both the conceptual 
knowledge (meaning of operations) and procedural knowledge (steps to follow in order to do an arithmetic operation). In this sense, and although the objective of the intervention is to automate procedural knowledge (so there are cognitive resources available), the importance of conceptual knowledge should be reminded. For example, it will be easier to eventually do a subtraction algorithm automatically if the principles of subtraction are understood.

It is important to take into account that to achieve automatization, repetitive practice is required and that children with LDM will need a higher number of repetitions. There are some materials and software very advisable to encourage this practice in a motivational environment. Educational software is particularly useful, as computation exercises are generally very tiring for children with LDM.

Moreover, there are some computation support activities we could do with daily materials (for more information, see Martínez, 2010). For example, two rules could serve to get used to doing subtractions. One of them will be the minuend and the other the subtrahend. In the subtraction operation 13-9, both rules would be overlapped in the mentioned numbers so that the zero in the second rule would be situated exactly above the solution of the subtraction, that is, 4 (see other interesting activities about mental calculation in Gálvez, Cosmelli, Cubillos, Leger, Mena, Tanter, et al., 2011).

An explicit instruction on counting strategies is very advisable for children with LDM, since they do not usually develop them automatically. This teaching method starts by showing the strategy to the child, verbalizing all the steps. Next, the reasons as to why this strategy is better should be explained, and lastly, the child should be told to do some exercises to practice it. Some examples of strategies which are useful in teaching are the following:

- Efficient computation: when doing an addition, it is better to start by the figure of higher value. For example, we will add three to the number 9 in the operation $3+9$.

- Understanding and using composition and decomposition out of context. For example, using tens to do an addition, e.g. $3+9=2+10=12$. 


\section{Problem Solving}

Improving problem solving is not a matter of doing more practical exercises but rather teaching solving strategies that will help a child develop specific competencies and make their performance better (Cabrera \& Campistrous,1999). Those strategies must be trained explicitly and appropriately to be applied to a wide range of problems (Castela, 2005).

In order to teach the problem solving process, teachers sometimes focus on the arithmetic operations which are implied in the problem. However, the complexity resides primarily in the semantic structure of the statement (Carey, 1991). In this sense, the teacher must take into account the importance of semantic structures of various problems on the pupils' ability to identify the operation required to solve them. For example, combined semantic structures are easier than compared problems (see Figure 2) and teachers must make explicit the different semantic structure and high or low complexity of them.

Example of combine problem (easy semantic structure): Mary has 3 pencils. Peter has 9 pencils. How many pencils do they have altogether?

Example of compare problem (difficult semantic structure): In a group there are 5 men more than the women. There are 15 men in the group. How many women are there?

Figure 2. Examples of different semantic structures.

Additionally, it is essential to teach strategies which are aimed at improving the representation, planning and reviewing processes implied in problem solving (Romero \& Lavigne, 2005). The supportive activities should be divided into steps (so that the representation process is reinforced and the statement understood) and end by asking the child to reread the statement and check the result (reviewing process). For instance, it is very effective to include a sentence at the end of each problem such as: Well 
done! But before moving on to the next exercise, it is very important to reread the statement and check if the answer you have given is possible.

Moreover, it should be highlighted that teaching problem solving processes should include different kinds of tasks and these tasks have to go beyond the classical view of a statement to be solved. In other words, the appropriate teaching strategy necessarily includes different kinds of problems, that is, problems with no exact solution, with unnecessary data, or with non-explicit data to be previously inferred by the student. Teachers could pose these questions to their students, which could be solved using the given data, or to discriminate between those questions which could or could not be solved with the given data.

Lastly, it is fundamental that the problems are significant for the students in order to improve their performance (Planas \& Iranzo, 2009). This means that problems should arouse the children's curiosity and interest so that they are willing to solve them from the very first moment. In this sense, the teacher should give practical examples and try to relate them to family and/or motivational situations.

Moreover, the teacher must ensure that the child has acquired all mathematical vocabulary, since sometimes this is the source of the problem (e.g. double or less than).

Regarding problem-solving assessment, the teacher has to focus not only on the final result the child has proposed, but on the analysis of the process as a whole, so that the root of the problem can be determined. In the following example, two different, incorrect answers have been proposed for the same statement: 'Maria has $\$ 9$ and buys a book that costs $\$ 7.25$; how much money does she have at the end?' A child suggests the solution 16.25 because they have just added the quantities that appear in the statement. Another one says the solution is 2.25 as they have not done the arithmetic operation correctly, although they chose the right type, subtraction (9$7.25=2.25$ ). The educational intervention would be different in each case despite the fact that both of them gave a wrong answer.

For this reason, it is advisable that teachers provide two grades for the correction of mathematical problems; one referring to the representation processes and the other to the operations.

As Sans (2010) points out, it is fundamental that both the teachers and the specialists treat a child together in order to adapt the curriculum to that particular student. This can be achieved by prioritizing objectives and 
giving the students some strategies and tools to compensate for their difficulties. They should be allowed to use an abacus, calculators or checking multiplication tables, as well as any other visual or graphic element which may help the student enhance their problem solving skills.

In conclusion, an efficient method of intervention in LDM should include an explicit teaching of different strategies, which regularly strengthen the acquisition of each step; telling the child how to proceed and use strategies of problem solving; proposing significant problems to the student which have different semantic structures; doing mathematical problems which don't always implement the same arithmetic operations; completing gaps with mathematical vocabulary and/or previous knowledge; promoting the habit of reviewing; and giving priority to tangible activities, and prioritizing the understanding of concepts and their relations over mechanical procedures.

\section{References}

Alsina i Pastells, À. (2007). ¿Por qué algunos niños tienen dificultades para calcular?: Una aproximación desde el estudio de la memoria humana. RELIME. Revista Latinoamericana de Investigación en Matemática Educativa, 10(3), 315-333.

Artigas, J. (2011). Trastornos del Neurodesarrollo. Barcelona: Editorial Narbona.

Berch, D. B. (2005). Making sense of number sense implications for children with mathematical disabilities. Journal of Learning Disabilities, 38(4), 333-339. doi: 10.1177/00222194050380040901

Blakemore, S.J., \& Frith, U. (2007). Cómo Aprende el Cerebro. Las Claves para la Educación. [How the Brain Learns. Keys for Education]. Barcelona: Ariel.

Bruno, A., Noda, M., Aguilar, R., González, C., Moreno, L., \& Muñoz, V. (2006). Análisis de un tutorial inteligente sobre conceptos lógicomatemáticos en alumnos con Síndrome de Down. RELIME. Revista Latinoamericana de Investigación en Matemática Educativa, 9(2), 211-226.

Butterworth, B., Varma, S., \& Laurillard, D. (2011). Dyscalculia: From brain to education. Science, 332(6033), 1049-1053. doi: 
Cabrera, C. R., \& Campistrous, L. A. (1999). Estrategias de resolución de problemas en la escuela. RELIME. Revista Latinoamericana de Investigación en Matemática Educativa, 2(2), 31-46.

Carey, D.A. (1991). Number sentences: Linking addition and subtraction word problems and symbols. Journal for Research in Mathematics Education, 22(4), 266-280. doi: 10.2307/749272

Castela, C. (2005). A propósito de los conocimientos que no se enseñan explícitamente, empero necesarios para tener éxito en las matemáticas escolares. RELIME. Revista Latinoamericana de Investigación en Matemática Educativa, 8(2), 111-128.

Chan, W. W. L., Au, T. K., \& Tang, J. (2014). Strategic counting: A novel assessment of place-value understanding. Learning and Instruction, 29, 78-94. doi: 10.1016/j.learninstruc.2013.09.001

Cohen Kadosh, R., Dowker, A., Heine, A., Kaufmann, L., \& Kucian, K. (2013). Interventions for improving numerical abilities: Present and future. Trends in Neuroscience and Education, 2(2), 85-93. doi: 10.1016/j.tine.2013.04.001

Defior, S. (1996). Las Dificultades de Aprendizaje: Un Enfoque Cognitivo. Málaga: Aljibe.

Dehaene, S. (1997). The Number Sense. New York: Oxford University Press.

Dehaene, S. (2011). The Number Sense: How the Mind Creates

Mathematics. New York: Oxford University Press.

Enright, B. (1989). Enright Diagnostic Inventory of Basic Arithmetic Skills.

North Billerica, Massachusetts: Curriculum Associates.

Gálvez, G., Cosmelli, D., Cubillos, L., Leger, P., Mena, A., Tanter, É., ... \&

Soto-Andrade, J. (2011). Estrategias cognitivas para el cálculo

mental. RELIME. Revista Latinoamericana de Investigación en Matemática Educativa, 14(1), 9-40.

Gross-Tsur, V., Manor, O., \& Shalev, R. S. (1996). Developmental dyscalculia: Prevalence and demographic features. Developmental Medicine and Child Neurology, 38, 25-33. doi: 10.1111/j.14698749.1996.tb15029.x

Kaufmann, L. (2008). Dyscalculia: neuroscience and education.

Educational Research, 50(2), 163-175. doi:

10.1080/00131880802082658 
Landerl K., Bevan A., \& Butterworth B. (2004). Developmental dyscalculia and basic numerical capacities: A study of 8-9 year old students.

Cognition, 93, 99-125. doi: 10.1016/j.cognition.2003.11.004

Martínez, J. (2010). Enseñar Matemáticas a Alumnos con Necesidades Educativas Especiales. Madrid: Wolters Kluwer.

Monuteaux, M.C., Faraone, S.V., Herzig, K., Navsaria, N., \& Biederman, J. (2005). ADHD and dyscalculia: Evidence for independent familial transmission. Journal of Learning Disabilities, 38 (1), 86-93. Doi: 10.1177/00222194050380010701

Ortiz, M.R. (2009). Manual de Dificultades de Aprendizaje. Madrid: Pirámide.

Otálora Sevilla, Y., \& Orozco Hormaza, M. (2006). ¿Por qué 7345 se lee como "setenta y tres cuarenta y cinco"? RELIME. Revista Latinoamericana de Investigación en Matemática Educativa, 9(3), 407-433.

Planas, N., \& Iranzo, N. (2009). Consideraciones metodológicas para la interpretación de procesos de interacción en el aula de matemáticas. RELIME. Revista Latinoamericana de Investigación en Matemática Educativa, 12(2), 179-213.

Radford, L., \& André, M. (2009). Cerebro, cognición y matemáticas. Revista Latinoamericana de Investigación en Matemática Educativa, 12(2), 215-250.

Romero, J.F., \& Lavigne, R. (2005). Dificultades de Aprendizaje: Unificación de Criterios Diagnósticos. Sevilla: Consejería de Educación de la Junta de Andalucía.

Sans, A. (2008). ¿Por Qué Me Cuesta Tanto Aprender?: Trastornos del Aprendizaje. Barcelona: Edebé.

Santiuste, J. S. \& González-Pérez, J. (2005). Dificultades de Aprendizaje e Intervención Psicopedagógica. Madrid: CCS.

Shalev, R.S. (2007). Prevalence of developmental dyscalculia. In D.B. Berch \& M.M.M. Mazzocco (eds.), Why Is Math So Hard for Some Children? The Nature and Origins of Mathematical Learning Difficulties and Disabilities (pp. 49-60). Baltimore: Brookes Publishing Co.

Shalev, R.S., \& Gross-Tsur, V. (2001). Developmental dyscalculia. Pediatric Neurology, 24(5), 337-342. 
Sowder, J. T. (1992). Estimation and number sense. In D. A. Grouws (Ed.), Handbook of research on mathematics teaching and learning (pp. 371-389). New York: Macmillan.

Gracia Jiménez-Fernández es profesora contratada doctora, del departamento de Psicología Evolutiva y de la Educación, en la Universidad de Granada, España.

Contact Address: La correspondencia directa sobre este artículo debe ser dirigida al autor. Dirección Postal: Facultad de Ciencias de la Educación. Campus Cartuja s/n 18071 Granada. Email: gracijf@ugr.es 